\title{
Modeling of a Forest Monitoring System to Control the Movement of Forest Materials Based on Radio-frequency Method
}

\author{
Andrey Pobedinsky ${ }^{1}$, Vladimir Pobedinsky ${ }^{2}$, and Sergey Sannikov ${ }^{2}$ \\ ${ }^{1}$ Northern Trans-Ural State Agricultural University, Tyumen, Russia \\ ${ }^{2}$ Ural State Forest Engineering University, Ekaterinburg, Russia
}

\section{Abstract}

Introduction. The article discusses the topical problem of designing a specialized forest resources tracking system. The analysis of domestic and foreign literature on the creation of monitoring information systems is carried out. One of the requirements for the system should take into account the instantaneous receipt of information about the state of the forest environment, take into account the specificity of the variability of many parameters of the forest environment, which may vary to a large extent, compliance with many rules regulated by legislation in the field of forest management.

Corresponding Author: Andrey Pobedinsky vm993711@.ru

Received: 25 October 2019 Accepted: 15 November 2019 Published: 25 November 2019

Publishing services provided by Knowledge E

(c) Andrey Pobedinsky et al. This article is distributed under the terms of the Creative Commons Attribution License, which permits unrestricted use and redistribution provided that the original author and source are credited.

Selection and Peer-review under the responsibility of the AgroSMART 2019 Conference Committee. On the basis of the requirements presented the system of RFID-devices. Materials and methods. The materials used were wireless sensors, an information system for information collection and notification. Methodological work is based on the theory of radio waves propagation of different frequencies, mathematical statistics and experimental theory. The results of the research are radio waves passing through a certain number of obstacles in the forest area, reflecting their geometric dimensions, determined by the parameter characterizing the occupancy of the channel resource, necessary for the transfer of information. Discussions and conclusions. The scientific novelty of the researches offers an information system of control over the forest resources, the monitoring of which is carried out continuously, taking into account all the necessary requirements, namely: the absence of harmful radiation, efficiency, energy consumption, durability, the propagation of radio waves at not prohibited frequencies for the Russian Federation, the definition of natural parameters, the detection of movement, the detection of fire at the initial stage.

Keywords: forest monitoring, radio frequency waves, modeling, forest resource control.

\section{Introduction}

Monitoring of forests, in particular its forest stands, is a long, painstaking work of forestry workers and forest loggers. This is due to the multitude of standing parameters with a combination of different external conditions in the forest area. The result of monitoring of parameters is an interconnected measured values of parameters obtained at certain intervals of time, during which the values of parameters do not change significantly [1]. 
An example of such parameters is the value of annual growth of wood in thickness and height, the inverse parameter of the tree is its withering and as a result the loss during a hurricane, fire or logging. Most of the existing tree stand monitoring methods use human resources and a handy measuring tool. Experience shows that a forest area can be located at a considerable distance from the people following the process, therefore, it is quite problematic to track changes that occur to the trees. It is necessary to have a forest monitoring system that can significantly reduce the number of people involved in forest monitoring, i.e. it is automated using technical means, information technologies. A monitoring system based on radio-frequency monitoring of the forest area can be used for this purpose [2].

The first modern generalized experience of system design was the "Guide to the body of knowledge on project management" (the Guide to PMVOC), developed in the 60 s by the firm Project Management Institute after the publication of several reports and discussions on this topic [6]. At present, the Guide has acquired the status of a global standard for project management, although many countries have developed their own national standards, similar to those of the RMVIOCs, including in Russia. The standard identifies the following processes: initiation, planning, organization and control (execution), monitoring and management, and completion. Prerequisites for the development of an automatic monitoring system for observations were published by $\mathrm{M}$. Drumlichem back in 1982 [7]. The basic design principles are formulated by N.P. Petrova in the methodology for designing environmental monitoring systems [8].

Practice shows that the problem is not solved only by legislative acts. Previous methods of forest movement control, which were used in Soviet times, and are widely used by modern specialists. These methods do not correspond to modern technologies of forest movement control. Modern methods should be based on the use of information automated systems. These systems require technical means (sensors) to help monitor the forest, as noted in the paper [4]. In order to receive timely information on the state of the forest, it is necessary to use various vehicles located on the ground, in the air and in space. On the other hand, the use of each type of vehicle is accompanied by difficulties, as there are no power supply sources in the forest. There is a need to find a solution to this problem and to use ground-based vehicles to control the forest in the movement of timber. 


\section{Methods and Equipment}

The system under development is a network of receiving and transmitting elements (sensors) located in the forest area in a certain way and working on the basis of radiofrequency tomography. Transmitters are placed at a certain distance from each other in the forest area under study. In this case, the arrangement of receivers and transmitters implies their location, which will maximize the real picture of changes in the forest area, at a given time or in a particular area.

A completely new way of monitoring the movement of forest materials is offered, using RFID devices and the sensors built into them. They are connected to a wireless network to collect information from RFID devices. The studies have helped to determine the parameters of the wireless network and RFID devices, which depend on the properties of the forest environment: the conductivity of the forest from the radius of the tree trunks, the ratio of dielectric permeability and electrical conductivity of the forest from humidity, the level of the field of dispersion of UHF waves in the forest from the distance for different species of trees. Parameters of the optimal amount of information transmitted in the wireless network have been determined, and the structural organization of the information network from RFID-devices has been studied (Fig. 1, [3]).

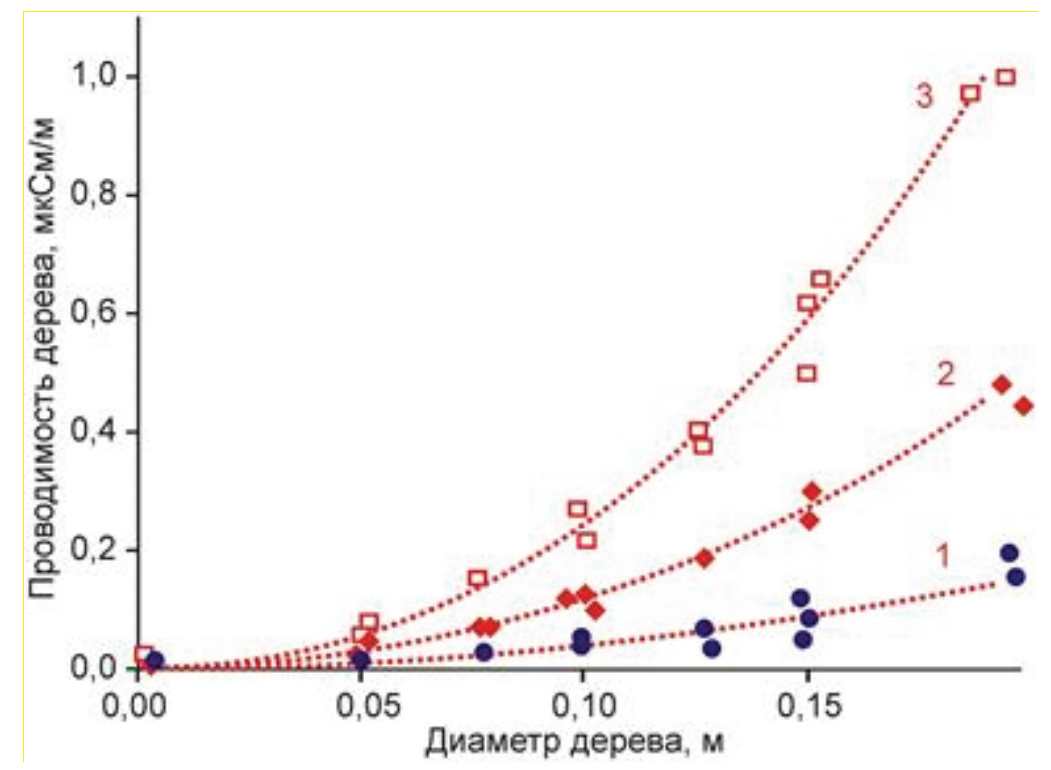

Figure 1: ПроВодимость леса со средним радиусом стВолоВ дереВьеВ: 1 -- береза; 2 -- ель; 3 -сосна.

The system uses a new approach to the movement of timber based on RFID devices that are wirelessly networked to collect information about changes in the condition of the wood in the forest. Each RFID device contains a tag that reports to the database all the parameters of the tree, including its location. The proposed RFID-based timber 
tracking system is in the research and study phase, and the initial results give hope for its successful application in forest management technology and forest management. Our research answers the question of how RFID devices will operate in the forest if the forest environment is known to affect radio waves. These studies have been conducted for radio communication and radar systems. The frequency range and power of RFID devices differ less from the above, but studies show that in some parts of the forest this is acceptable and appropriate to control the movement of timber by interconnecting all devices in a wireless network. The volume of the Vc information signal in the transmission system is expressed by the ratio:

$$
V c=T \cdot \Delta F c \cdot Д
$$

where

$T$-- data signal duration;

FC -- transmit spectrum width;

$\triangle=10 \lg (P / N)$-- dynamic signal range;

$P$-- signal strength;

$N$-- number of messages.

The lifetime of a radio signal in a wireless RFID network channel is determined by its duration, and the spectrum width indicates the frequency range in which the main energy emitted by the radio transmitter is concentrated, as shown in Figure 2.

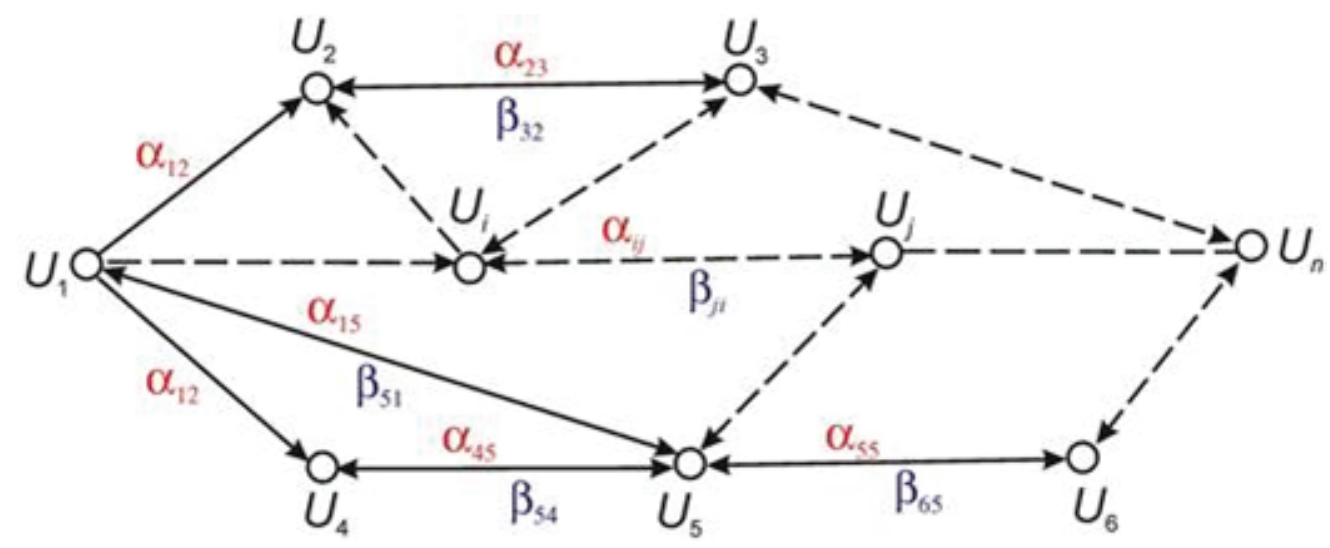

Figure 2: Information network diagram from RFID devices; $U$-- network node; $\alpha, \beta$-- signal.

The information collected from the sensors can be displayed in a convenient way for the operator (either in the form of graphs, tables or otherwise). The use of this system does not imply constant tracking of readings by the operator, as they will be recorded on an electronic medium (electronic memory), which will allow at any time to get access to the necessary time period. Thanks to the collected data, for a certain period of time, allows you to model the scheme (paintings, plans, maps) of the location of trees on 
the ground and calculate the change in geometric values, such as diameter. Since the measurement results are preserved, it is possible to track what happened to the forest area, to the individual tree during the dry season, in the rainy season, after fires and floods, etc. In addition, the system under development allows tracking the movement of timber and the occurrence of forest fires.

The proposed system requires mathematical simulation of some structural and design parameters. For this purpose, it is possible to use a radio signal scattering matrix [3] from RFID devices located along the perimeter of the forest area under study, as shown in Figure 3.

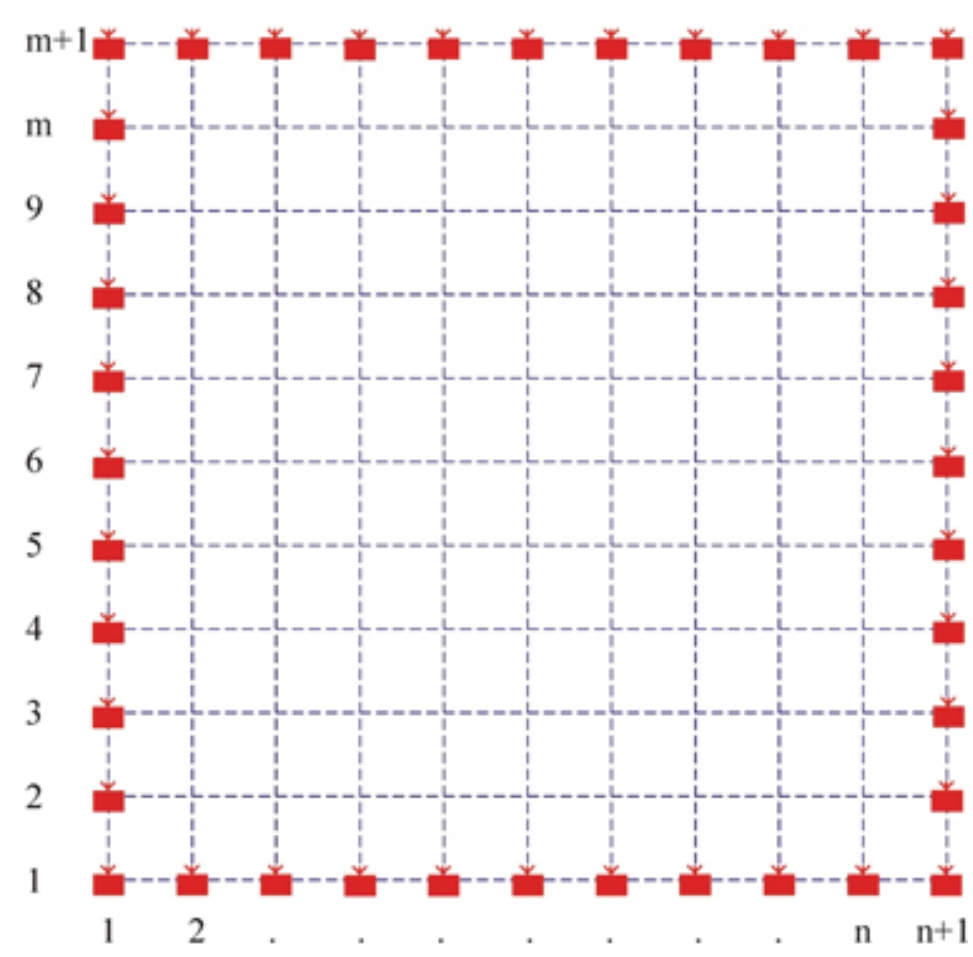

Figure 3: Layout of RFID devices in the forest area under study.

\section{Results}

As you can see in the fig. 3 The area under study represents the matrix, when receiving and transmitting a signal between each RFID device. The magnitude of the electromagnetic wave scattering by the trees (not shown in the figure) that stand in the way of this signal propagation. By analyzing these signals, it is possible to judge the presence of individual trees, their location on the ground (by coordinates) and even their geometric dimensions, as shown in Figure 4.

The dynamic range of energy in a radio signal characterizes the ratio of the highest instantaneous signal power $(P \max =P$ ) to the lowest $(P \min )$, the permissible value of 


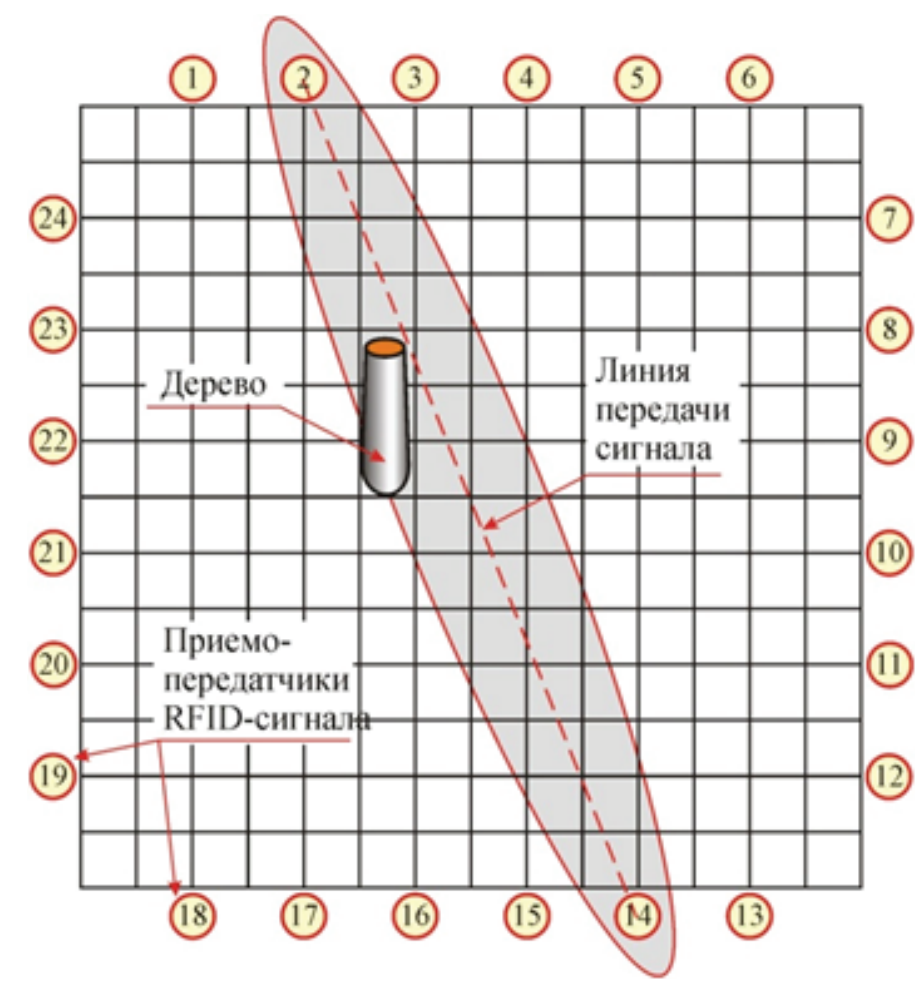

Figure 4: RFID signal scattering from the source to the receivers.

which is determined by the interference power $\mathrm{Pn}(\mathrm{Pmin} \geq \mathrm{Pn})$. The characteristics of "useful" radio signals are determined by the requirements for the channel elements of the network, for example, for an undistorted information signal the capacity of the channel resource must be not less than the volume of transmitted information signal.

An important parameter of the radio signal that characterizes the fill rate of the channel resource is the "base" (width) [2]:

$$
v=2 T \cdot \Delta F c,
$$

where $v \leq 1$-- radio signals called narrowband (simple);

V >> 1 -- broadband (complex).

\section{Discussion}

The proposed system uses UHF radio waves, which means that harmful radiation is virtually absent and therefore has no negative impact on the environment.

From the economic point of view, the system of forest monitoring based on radiofrequency tomography can not be very expensive, because the use of tomographs in other industries for more than thirty years, such as medicine, electronics, physics, and, 
having understood the basic principle of operation of this device, to develop their own system of forest monitoring is very useful and appropriate.

\section{Conclusion}

The issues related to the relevant research topic are presented and solved:

1. radio wave propagation of RFID devices in the ranges of 0.9 and $2.4 \mathrm{GHz}$;

2. influence of forest environment on radio waves propagation under canopy and in tree canopy;

3. justification of the parameters of the forest environment and RFID-devices, when used for the movement of timber, early detection of forest fires and their prerequisites.

Solutions to these problems can be used in practice in the design of forest information collection systems and timber movement.

\section{References}

[1] Sannikov, S.P., Hertz, E.F., Dyachkova, A.A. (2016). Methodology of remote monitoring of woodstands and wood transport flows. Forestry journal, pp. 109--115. Arkhangelsk, S(A)FU. Retrieved from: http://narfu.ru/university/library/books/2780.pdf (contact date: 20.10 .2018$)$.

[2] Pobedinskiy, A.A. (2018). Justification of parameters of the system of radio-frequency monitoring of the forest fund. PhD dissertation thesis. Yekaterinburg, $18 \mathrm{p}$.

[3] Giuli. (1985) Polarization diversity in radars. IEEE, vol. 74, no. 2.

[4] Sannikov, S.P. (2015). Fundamentals of the automated control of the timber movement using the RFID devices integrated into the local wireless network. Modern problems of science and education, no. 1--1. Retrieved from: http://www.science-education.ru/ 121-18960 URL: http://elibrary.ru/download/51177804.pdf (accessed on 19.09.2018).

[5] Technologies for tracking the movement of wood products. Supply chain control and monitoring in the forest industry. World Wildlife Fund. (2004). Moscow, p. 68. Retrieved from: http://www.wwf.ru (accessed on 19.09.2018).

[6] American National Standard ANSI/PMI 99-001-2004. (2013). A Guide to the Project Management Body of Knowledge (PMBOK Guide). 5th edition of the Project 
Management Institute, p. 614. Retrieved from: http://pm-files.com/sites/default/files/ file/C/C-1/C-1-1/pmbok_5th_2013_rus.pdf

[7] Drumlic, M., lovanovich-Kurepa, M. (1982). Automatic monitoring system for observation of air pollution in air basins. Moscow, p. 14.

[8] Petrova, N.P., Popov, N.S., Luzgachev, V.A. (2014). To the methodology of the environmental monitoring systems design. TSU Bulletin, vol. 19, iss. 5. pp. 1712-1716.

[9] Vasin, V.V., Stepanov, B.M. (1977). Zadachnik on radiolocation. Moscow: Soviet Radio, p. 321.

[10] Pobedinskiy, V.V., Gazizov, A.M., Sannikov, S.P., Pobedinskiy, A.A. (2018). Dielectric permeability of the forest fund depending on the environment parameters at the radio-frequency monitoring. Vestnik. Mord. unit., vol. 28, no. 2, pp. 148--163. DOI: https://doi.org/10.15507/0236-2910.028. 201802.148-163.

[11] Pobedinskiy, V.V., Kruchininin, I.N., Pobedinskiy, A.A. (2018). Intellectual system of determination of forest environment dielectric permeability at radio frequency monitoring. Izvestiya Samara Scientific Center of the Russian Academy of Sciences, vol. 20, no. 6(2), pp. 383--390.

[12] Richter, J., Caldeirinha, R.F.S., Al-Nuaimi, M.O., Seville, A., Rogers, N.C., Savage, N. (2005). A generic narrowband model for radiowave propagation through vegetation, 2005 IEEE. 61 $1^{\text {st }}$ Vehicular Technology Conference (VTC 2005-Spring), vol. 1, pp. 39-43 (30 May -- 1 June).

[13] Hashim, M.H., Stavrou, S. (2006). Wind influence on radiowaves propagating through vegetation at $1.8 \mathrm{GHz}$. IEEE Antennas and Wireless Propagation Letters, vol. 4, 143-146.

[14] Lloret, J., Garcia, M., Bri D., Sendra, S. (2009). A Wireless Sensor Network Deployment for Rural and Forest Fire Detection and Verification. Sensors, no. 9, pp. 8722--8747. Retrieved from: http://www.mdpi.com

[15] Doolin, D.M., Sitar, N. (2005). Wireless sensors for wildfire monitoring. In Smart Structures and Materials 2005: Sensors and Smart Structures Technologies for Civil, Mechanical, and Aerospace Systems, San Diego, CA, USA (7 May).

[16] Lloret, J., Tomas, J., Garcia, M., Canovas, A. (2009). A hybrid stochastic approach for self-location of wireless sensors in indoor environments. Sensors, no. 9, pp. 3695-3712.

[17] Gay-Fernandez, J.A., Sanchez, M.G., Cuinas, I., Alejos, A.V. (2010). Propagation Analysis and Deployment of a Wireless sensor Network in a Forest. In Electromagnetics Research, vol. 106, pp. 121--145. Retrieved from: http://www.jpier. org 
[18] Meng, Y.S., Lee, Y.H., Ng, B.C. (2010). Path loss Modeling for Near-ground VHF Radiowave Propagation through Forests with Tree-Canopy reflection Effect. Progress In Electromagnetics Research, vol. 12, pp. 131--141.

[19] Standards of series IEEE 802. Retrieved from: http://tomas02.narod.ru (20.05.2013).

[20] Forest Code of the Russian Federation. Retrieved from: http://www.leskod.ru. 